\title{
LAND USE INDICES FROM SMMS DATA IN WESTERN THAILAND
}

\author{
Uten Thongtip ${ }^{1}$
}

\begin{abstract}
This applied research was conducted by employing both quantitative and qualitative innovative research methods. This research investigates the satellite data of four spectral bands sent from the Small MultiMission Satellite (SMMS). Each band was analyzed to create color composition indices of the western areas of Thailand. Band 1 had a wavelength between 0.43 and 0.52 micrometers, Band 2 between 0.52 and 0.60 micrometers, Band 3 between 0.63 and 0.69 micrometers, and Band 4 between 0.76 and 0.90 micrometers. Three layers of satellite data were overlaid in non-repeating arrangements. Bands showing grayscale were substituted by three additive primary colors of blue, green, and red. The arrangements were permutated into 24 indices: 123 , $124,132,134,142,143,213,214,231,234,241,243,312,314,321,324,341,342,412,413,421,423,431$, and 432. The data of color composition indices were then analyzed to create the land-use indices. The visual interpretation of the three levels of land-use classification were used in this procedure. The result was a land-use classification with 15 indices: City, Commercial, and Services; Airport; Golf Course; Paddy Field; Field Crop; Perennial; Aquacultural Land; Shrimp Farm; Evergreen Forest; Deciduous Forest; Mangrove Forest; Marine; River; Canal; Reservoir; and Road.
\end{abstract}

UDC Classification: 910.1 DOI: http://dx.doi.org/10.12955/cbup.v4.804

Keywords: color composition index, land-use index, SMMS data.

\section{Introduction}

The National Research Council of Thailand (2011) formulated the eighth National Research Policy and Strategy (2012-2016), which commanded high quality research towards a new body of knowledge to develop the country. This supports the potential to improve research works and new innovations as well as enhancements to new knowledge in social science and geo-information for a balanced and sustainable national development.

The Small Multi-Mission Satellite (SMMS) is an Earth observation satellite under the cooperation of Thailand and China. With its ability to record color images (resolution of 30 square meters), it is suitable for monitoring disasters and land-use classifications. Further, satellite data are provided free of charge by the Ministry of Information and Communication Technology of Thailand for academic purposes (Kasetsart University and Ministry of Information and Communication Technology, 2011).

In May 2013, SMMS data from 33 organizations and educational institutions concerning geoinformation database management in the west of Thailand was surveyed. The results revealed that organizations and educational institutions were facing problems regarding land-use classifications. Moreover, color composition indices and land-use classification indices from SMMS data were needed. To this end, this study aims to develop color composition and land-use classification indices for use in analyzing land use. In addition, the study will identify the best practice for rapid, economical, and effective satellite data analysis. The study complies with the eighth National Research Policy and Strategy under the topic of Integration of Research promoting national development, policy, and strategy; and Research for Academic Excellence promoting the development of innovation, using science, technology, and geo-information relating to knowledge likely to result in balanced and sustainable national development.

\section{Methods}

The study involved applied research with the combination of innovative qualitative and quantitative methods. The research procedures involved retrieving four bands of SMMS data with the spatial resolution of 30 square meters, comprising Band 1, Band 2, Band 3, and Band 4; and digital data for land-use statuses of urban or built-up land, agriculture land, forest land, water body, and miscellaneous land, and digital spatial data for boundaries, streams, and roads.

\footnotetext{
${ }^{1}$ Uten Thongtip, Department of Geographical Technology, Faculty of Humanities and Social Sciences, Phranakhon Rajabhat University, Thailand, tane_geog@hotmail.com
} 
Color composition indices, using four bands of SMMS data (Band 1, Band 2, Band 3, and Band 4) were created. Three bands of satellite data were overlaid in non-repeated arrangements, using a permutation method. Each band was substituted by three additive primary colors (red, green, and blue).

Land-use classification indices from SMMS data were created, followed by a complete cycle interpretation. Factors for interpretation were size, shape, texture, shadow, shade and tone, pattern, and location and environmental. Three levels of land-use classification indices were created, using principles of Anderson, Hardy, Roach, and Witmer (1976) and land-use classification systems in accordance with standard land-use classification of the Office of Soil Resources Survey and Research of Thailand (2011). Level 1 consisted of marine and road; Level 2 of city, town, and commercial; paddy field; field crop; perennial aquacultural land; water body; evergreen forest, deciduous forest, and mangrove forest. Level 3 consisted of airport, harbor, industrial estate, golf course, shrimp farm, river, canal, and reservoir.

Accuracy of land-use classification indices were analyzed, using error matrix, which accepted accuracy for formulating land-use classification indices in accordance with the standard land-use classification and land cover from long-distance observation data at the minimum accuracy level of 85 (Anderson, 1971; Getimis, Spanidis, Van Den Born, \& Kroon, 1999).

\section{Results}

The development of color composition indices from SMMS data required an analysis of the potential levels of color composition indices and then the creation of new color composition indices.

Table 1 shows overall potential levels of color composition indices in three dimensions, including policy relevance, analytical soundness, and measurability. The three dimensions had the same potential level of 4.85 , which is a "very high" level of potential index.

Table 1: Overall potential levels of color composition indices

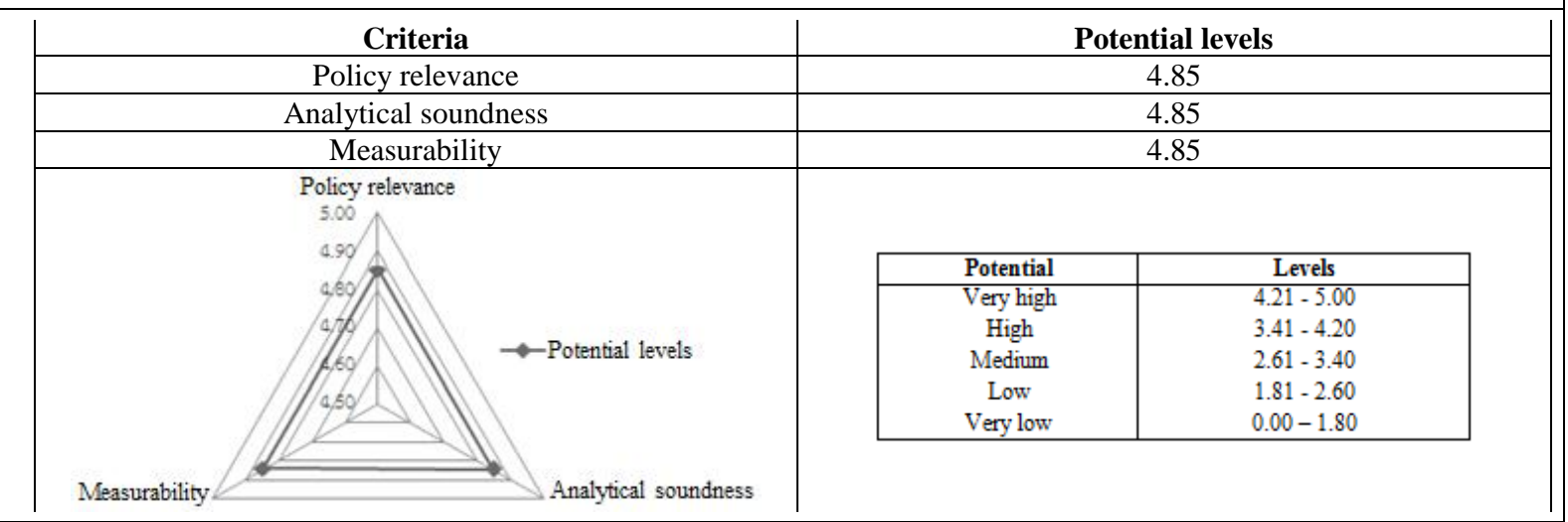

Source: Author

The 3-band satellite data was composed to create additive color composite images for image enhancement. New colors were created from data of various bands, using the technique of creating additive color for composite images from three spectrum colors, namely, red, green, and blue. The arrangements were permutated into 24 indices $(123,124,132,134,142,143,213,214,231,234,241$, $243,312,314,321,324,341,342,412,413,421,423,431$, and 432).

The creation of land-use classification indices from SMMS data involved the accuracy of the land-use classification, the analysis of land-use classification indices' potential, and the creation of land-use classification indices.

Figure 1 shows the accuracy levels for individual indices of the land-use classification, and thus the classification overall, were above $85 \%$, the highest acceptable level in accordance with the standard of land-use and land cover classification from satellite data. 
Figure 1: Accuracy of land-use classification from Small Multi-Mission Satellite data

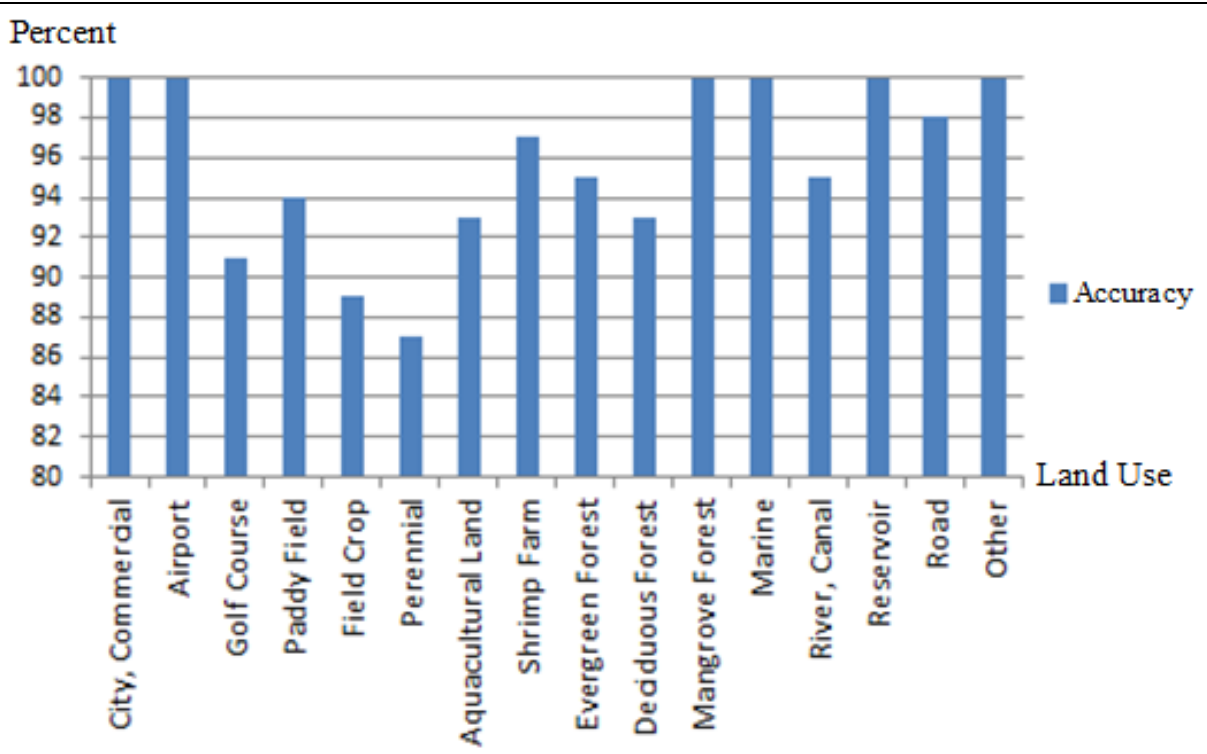

Source: Author

Table 2 reveals the potential levels of analytical soundness. The data were based on expert opinion from personnel of the involved organizations. The policy relevance had a potential level of 4.87, the analytical soundness 4.86 , and measurability 4.84 . The potential levels of all dimensions were rated "very high".

Table 2: Overall potential levels of land-use classification indices

\begin{tabular}{|c|c|c|}
\hline Criteria & \multicolumn{2}{|c|}{ Potential levels } \\
\hline Policy relevance & \multicolumn{2}{|c|}{4.87} \\
\hline Analytical soundness & \multicolumn{2}{|c|}{4.86} \\
\hline Measurability & \multicolumn{2}{|c|}{4.84} \\
\hline $\begin{array}{l}\text { Policy relevance } \\
5.00\end{array}$ & $\begin{array}{c}\text { Potential } \\
\text { Very high } \\
\text { High } \\
\text { Medium } \\
\text { Low } \\
\text { Very low } \\
\end{array}$ & $\begin{array}{c}\text { Levels } \\
4.21-5.00 \\
3.41-4.20 \\
2.61-3.40 \\
1.81-2.60 \\
0.00-1.80 \\
\end{array}$ \\
\hline
\end{tabular}

Source: Author

The creation of land-use classification indices, using principles of Anderson et al. (1976) and two levels of standard land-use classification (Level 1 and Level 2), generated 15 indices of land-use classification, including city, commercial, and services (U1), airport (U401), golf course (U602), paddy field (A1), field crop (A2), perennial (A3), aquacultural land (A9), shrimp farm (A903), evergreen forest $(\mathrm{F} 1)$, deciduous forest $(\mathrm{F} 2)$, mangrove forest (F3), marine (W1), river and canal (W101), reservoir (W201), and road (R).

\section{Discussion}

This study reached its objective in the creation of color composition indices and land-use classification indices. System theory played an important part in producing the successful results. The data were systematically imported and processed, resulting in tailor-made outcomes for each area. In addition, the results were adjusted in accordance, with recommendations to gain completed and applicable results. According to 401 participants, color composition indices and land-use classification indices 
created in this study have high potential and are suitable for application. However, the study had some limitations. The color composition indices could not be used or applied with high-resolution data, retrieved from other satellites in Thailand. The land-use classification indices could not be used or applied in all areas of Thailand because, in some areas, there were specific types of land-use that were unavailable in this study.

\section{Conclusion}

The study of creating land-use classification indices from SMMS data in western areas of Thailand provided color composition indices of SMMS data with very high potential in all three dimensions, namely, policy relevance, analytical soundness, and measurability. The study generated 24 color composition indices, including 123, 124, 132, 134, 142, 143, 213, 214, 231, 234, 241, 243, 312, 314, $321,324,341,342,412,413,421,423,431$, and 432.

The land-use classification indices from SMMS data in western areas of Thailand have very high potential in all three criteria, which were policy relevance, analytical soundness, and measurability. The accuracy levels of both the overall and the specific land-use classifications were above 85\%, which is the highest acceptable level. The study generated 15 indices including city, commercial, and services; airport; golf course; paddy field; field crop; perennial; aquacultural land; shrimp farm; evergreen forest; deciduous forest; mangrove forest; marine; river; canal; reservoir; and road.

\section{Acknowledgements}

The study of land-use indices from SMMS data in western Thailand has been given scholarship from Phranakhon Rajabhat University of Thailand in the fiscal year of 2014.

\section{References}

Anderson, J. R. (1971). Land Use Classification Schemes Used in Selected Recent Geographic Applications of Remote Sensing. Photogram, 37 (4), 379-387.

Anderson, J. R., Hardy, E. E., Roach, J. T. \& Witmer, R. E. (1976). A Land Use and Land Cover Classification System for use with Remote Sensor Data. Washington: United States Government.

Getimis, P., Spanidis, N., Van Den Born G. J. \& Kroon, H. J. J. (1999). Land Use Pressure Indicators. Greece: Greece National Focal Point GIS Laboratory.

Kasetsart University and Ministry of Information and Communication Technology (2011). SMMS: Perspectives and Applications from Space. Bangkok, Thailand: CHRS.

National Research Council of Thailand (2011). National Research Policy and Strategy (2012-2016). Bangkok, Thailand: National Research Council of Thailand.

Office of Soil Resources Survey \& Research (2011). Land Use Classification Guide. Bangkok, Thailand: Land Development Department. 